\title{
Isolation and Molecular Identification of Foot and Mouth Disease Virus Circulating Around Central Ethiopia
}

\section{Bisratgebriel Tesfaye Muchie}

Veterinary Drug and Feed Administration and Control Authority

Ashenafi Kiros Wubshet

Lanzhou Veterinary Research Institute https://orcid.org/0000-0002-9008-2075

\section{Aklilu Feleke Haile}

Aklilu Lema Pathobiology institute, Addis Ababa University

\section{Hayelom Michael Deyo}

Adminstration for refugee and returnee, Addis Abba, Ethiopia

\section{Kazimierz Tarasiuk}

University Center of Veterinary JU-AU PL

\section{Zygmunt Pejsak}

University Center of Veterinary JU-AU PL

Zhang Jie ( $\sim$ Zhangjie03@caas.cn )

Lanzhou Veterinary Research Institute

\section{Research}

Keywords: BHK-21 cell culture, FMD virus, PCR, Outbreak, Serotype

Posted Date: June 7th, 2021

DOl: https://doi.org/10.21203/rs.3.rs-436692/v1

License: (9) This work is licensed under a Creative Commons Attribution 4.0 International License.

Read Full License 


\title{
Isolation and Molecular Identification of Foot and Mouth Disease Virus Circulating around Central Ethiopia
}

\author{
Bisratgebriel Tesfaye Muchie $^{1}$, Ashenafi Kiros Wubshet ${ }^{4,5}$, Aklilu Feleke Haile ${ }^{2}$, Hayelom \\ Michael Deyo ${ }^{7}$ Kazimierz Tarasiuk $^{5}$, Zygmunt Pejsak ${ }^{6}$, Zhang jie $^{3 *}$ \\ tesfayezenaw@yahoo.com (B.T.M), atakilu@yahoo.com (A.F.H), nafikw@gmail.com (A.K.W), \\ hmike98@gmail.com (H.M.D), zpejsak@o2.pl (Z,P), Zhangjie03@caas.cn (J.Z.) \\ * Correspondence: Zhangjie03@ caas.cn (J.Z.); \\ Ashenafi Kiros Wubshet- nafikw@gmail.com Tel.: +251-934504267 \\ ${ }^{1}$ Veterinary Drug and Feed Admisntration and Control Authority, Addis Ababa, Ethiopia. \\ ${ }^{2}$ Aklilu Lemma Institute of Pathobiology, Addis Ababa University, Addis Ababa, Ethiopia.. \\ ${ }^{3}$ State Key Laboratory of Veterinary Etiological Biology, National/OIE Foot and Mouth Disease \\ Reference Laboratory, Lanzhou Veterinary Research Institute, Chinese Academy of Agricultural \\ Sciences, Lanzhou 730046, China \\ ${ }^{2,4}$ Department of Veterinary Basics and Diagnostic Sciences',College of Veterinary science (CVS), \\ Mekelle University, Tigray, Ethiopia. \\ ${ }^{5}$ University center of veterinary medicine JU-AU, PL 30-059 Kracow, AI. Mickiewicza 24/28 \\ ${ }^{6}$ Administration for Refugee and Returnee Affair(ARRA) Addis Ababa, Ethiopia.
}

\section{Abstract}

Background: Foot and mount disease (FMD) is a highly contagious, economically and politically significant transboundary animal disease which specifically affects all cloven-hoofed animals; cattle, pig, goat, sheep and many wild artiodactyls. Five of the seven (O, A, C, SAT1, SAT2, SAT3 and Asia 1) serotypes of FMD virus (O, A, C, SAT1, SAT2) are endemic in Ethiopia; however, limited information on the current FMDV status and the circulating serotype is available in the country. Therefore, this study was conduct to isolate and molecularly identify the FMD viruses using a panel of virological detection assays.

Methods: An outbreak-based cross-sectional study was conducted in Addis Ababa and Bishoftu during 2013 and 2014 to isolate and to molecularly identify the circulating serotype of FMDV. A total of 20 samples were collected from clinically infected cattle and pigs during the outbreak and virus isolation and molecular serotype identification was carried out at the National Veterinary Institute (NVI), Bishoftu Ethiopia. Cells were monitored for cytopathic effects (CPE) daily and frozen when CPE were developed. Serotyping of FMD viruses were made by applying classical PCR from cell cultures showing CPE.

Results: All tested samples showed cytopathic effect (CPE) on BHK-21 cell culture and serotype $\mathrm{O}$ was identified using PCR. The DNA bands were visualized to the expected sizes. 
Conclusions: Based on these result, a continuous understanding of the molecular epidemiology of the disease along with the proper vaccination matching for the circulating serotype; $\mathrm{O}$ is critical for implementation effective control and prevention programs eventually for the eradication of the disease.

Keywords: BHK-21 cell culture, FMD virus, PCR, Outbreak, Serotype

\section{Background}

Foot and mouth disease (FMD) is one of the most important transboundary animal diseases that cause severe economic losses due to high morbidity and export trade restrictions imposed on affected countries. The economic crises as result of FMDV is unproportional in different setting through the world [1], because the disease significantly varies in; FMD endemic and nonendemic, developed and within developing countries [2]. The livestock income in Africa, China, and India is mostly affected by FMD and Africa alone lost about 2.32 billion US dollar from direct production losses and vaccination [1].

Particularly, in Ethiopia, FMD is one of the major livestock diseases of socio-economic importance. Recently, the disease had become the major constraint hampering export of livestock and livestock products to the Middle East and African countries; the Egyptian trade ban of 2005/2006, in which Ethiopia lost more than US\$14 million being a recent memory [3].

This disease is highly contagious and can infect more than 70 cloven-hooved animal species [4], such as cattle, pigs, goat and sheep and many wild artiodactyls in 80 or more countries [5]. Generally, the infection rate of FMD can be mainly affected by factors such as the animal species, animal breed, host-immunity status, and virus infection titer [6]. There is no question with morbidity rate in which all susceptible animals exposed to FMD $100 \%$ develop the disease $[6,7]$. But, mortality rate varies in different species and age groups; $5 \%$ to $94 \%$ in lambs, $80 \%$ in some groups of calves, and $100 \%$ in suckling piglets and $1-5 \%$ in most adult animals [8].

FMD typically characterized by rapid genetic evolution, its contagious nature, various modes of transmission (direct contact, airborne, and via fomites) $[9,10]$. Thus, it is classified as an OIE list a disease (notifiable disease). FMDV belongs to the Aphthovirus genus as a member of the 
Picornaviridae family [11]. The continual viral evolution of the etiological agent, FMD virus (FMDV), revealed into seven major serotypes; A, O, C, Asia1, South African Type (SAT1, SAT2, and SAT3) has been classified into seven serotypes with distinct antigenic properties and specific distribution patterns across the globe $[12,13]$. All these serotypes infect cloven-hoofed animals. Infection with any one of these serotypes will not confer immunity against the other serotypes. Many subtypes can be identified by biochemical and immunological assays [14]. The virus seems to be capable of infinite mutations so that new antigenically different types constantly appear. As there is no cross-protection among serotypes, immunity to one type does not confer protection against any of the other six types. In addition, there might be great changes in antigenicity between emerging serotypes [15]. Therefore, difficulties in vaccine development are obvious.

The disease are characterized by fever, excessive salivation, and vesicles on the tongue especially in small ruminants in which clinical signs often milder depending on the strain of virus. The disease is endemic to most countries in sub-Saharan Africa where six of seven serotypes are prevalent, and virus circulates between wild hosts and domestic animals [16]. Five of the seven serotypes of FMDV (O, A, C, SAT2, SAT1) are endemic in Ethiopia [13, 16, 17, 18]. Currently, in Ethiopia there is no government strategy in FMD control through vaccination and movement control [19].

In Ethiopia, the livestock species are at risk from endemic strains as well as from antigenic variants prevailing in neighboring countries. The disease occurred frequently in pastoral herds in the low land areas of Ethiopia [20], but in recent years, the incidence of this disease has increased and became apparent in the high land areas where $60 \%$ of the total livestock population habitat.

A continues understanding of the molecular epidemiology of the disease is critical for implementation effective control and prevention programs eventually for the eradication of the disease. Therefore, this study was conduct to isolate and molecularly identify the FMD viruses using a panel of virological detection assays. During outbreaks, it is also important to identify the origin of infection and its relationship to vaccines available for protection, which assist in planning a control program in the country. 


\section{MATERIAL AND METHODS}

\section{Study area}

The study was conducted from September 2013 to May 2014 at Debrezeit, East shoa, Oromia region and around Addis Ababa located in the Central parts of Ethiopia. Debrezeit is the town of Ada'a district located about $47 \mathrm{~km}$ South East of Addis Ababa, the capital city of Ethiopia at $9^{\circ} \mathrm{N}$ and $40^{\circ} \mathrm{E}$ with an altitude of $1850 \mathrm{~m}$ above sea level. Addis Ababa is the capital city of Ethiopia with an altitude of 7,546ft (2,300 meters) above sea level and has subtropical and highland climate. The livestock production systems in these areas are both intensive and extensive type.

\section{Study population and Sampling method}

The study populations were bovine and swine, which manifested clinical signs of FMD. The investigation of the outbreak was conducted in Bishoftu and Addis Ababa. A total of 10 cattle and 10 pigs were found clinically infected. The tissue samples were collected purposely from infected bovine and swine species.

\section{Clinical examination}

For each outbreak's sample, animals were clinically examined for presence of typical vesicular lesions on the mouth, on the feet, teats and lameness.

\section{Sample collection}

Twenty epithelial tissues were collected from unruptured or freshly ruptured vesicular lesions on tongue of clinically infected animals and samples were placed in a tube with transport medium composed of equal amounts of glycerol and $0.004 \mathrm{M}$ phosphate-buffered saline solution at $\mathrm{pH}$ 7.2-7.6 with antibiotics [14]. The tubes were labeled with identification numbers, species name, sex, age, site of collection and location in the study area. All samples were immediately placed in the icebox and transported to National Veterinary Institute (NVI), Bishoftu Ethiopia. Once the samples arrived at NVI, they were stored at $-20 \mathrm{oC}$ until processed or shipped. From the 20 
samples that showed CPE, 12 (7 sample from Bishoftu and 5 samples from Addis Ababa) were selected for molecular serotyping as detailed in Table1. Serotype $\mathrm{O}$ was identified from a total of 5 and 7 samples in bovine and swine species respectively, in and around Addis Ababa and Debrezeit.

\section{Virus isolation and Serotype identification}

The frozen epithelial tissues were thawed at room temperature and washed three times using sterile phosphate-buffered saline (PBS) at a pH of 7.2-7.6 under laminar airflow hood class II. Approximately, $1 \mathrm{~g}$ of epithelial tissue sample was grounded using sterile mortar and pestle by adding $10 \mathrm{ml}$ of sterile PBS containing antibiotic. The tissue suspension was centrifuged at 3,000rpm for $10 \mathrm{~min}$. The supernatant was collected and filtered by Millipore filter of $0.45-$ micrometer pore size. About $1 \mathrm{ml}$ of filtered tissue suspension was inoculated on baby hamster kidney (BHK-21) monolayer cells grown on $25-\mathrm{cm} 2$ tissue culture flask and then flashed with growth media and incubated at $37^{\circ} \mathrm{C}$ and $5 \% \mathrm{CO}_{2}$ in a humidified incubator for 48 hours. Cells were monitored for cytopathic effects (CPE) daily and frozen when CPE were developed. Serotyping of FMD viruses were made by applying classical PCR from tissue suspension and cell cultures showing CPE.

\section{Extraction of virus RNA}

Total RNA was extracted from the tissue suspensions and cell culture isolates by using RNeasy mini kit (Qiagen, Germany) based on the manufacturer's protocol. Briefly, $460 \mu 1$ tissue suspension or tissue culture samples were taken and placed in to a $1.5 \mathrm{ml}$ eppendorf tube, followed by addition of an equal volume of lysis buffer RLT (containing 1\% 2-mercaptoethanol). The mixture was vortexed and incubated at room temperature for $5 \mathrm{~min}$. The sample was also mixed intermittently during the incubation period and $460 \mu 1$ of $70 \%$ ethanol was added into the mixture and vortexed. The mixture was transferred to RNeasy spin column (700 $\mu 1$ maximum loading volume) and spun in a microfuge for 15 second at 13,000 rpm. The flow-through was discarded and repeated with remaining volume. The RNA was washed with $700 \mu$ washing buffer1 (centrifuge for 15 second at 13,000rpm) followed by washing with $500 \mu$ l washing buffer. The column was centrifuged at 13,000rpm for 2 min to dry the silica membrane and RNA was eluted with $50 \mu 1$ RNase free-water in to a new clean RNase free eppendorf tube. Average 
concentration of the total nucleic acid RNA in NanoDrop ranges from 120-260 ng/uL and the pure RNAs were used for cDNA synthesis or stored at $-20 \mathrm{oC}$ until needed.

\section{Complementary DNA synthesis (cDNA)}

The fresh extracted DNA was used as template to synthesis a complementary DNA using cDNA Synthesis Kit (Invitrogen, USA) according to the manufacturer's protocol. Total of 20- $\mu$ l reaction volume was prepared for cDNA synthesis. Primarily $2 \mu 1$ oligo T primer, $2 \mu 1$ Random Hexamers, $1 \mu 1$ of $10 \mathrm{~m}$ dNTPs and $5 \mu 1$ RNA added to $0.5 \mathrm{ml}$ PCR tube and incubated at $68^{\circ} \mathrm{C}$ for 3 minutes (PCR machine) and chilled on ice for 3 minutes. Then 10x RT buffer, 25mM MgCL 2 , 0.1M DTT and Superscript III (Reverse transcriptase) were added with the rate of $2 \mu 1,4 \mu 1,2 \mu 1$ and $1 \mu \mathrm{l}$, respectively, and incubated at $42^{\circ} \mathrm{C}$ for 2 minutes. Finally, RNase out were added and incubate at $42^{\circ} \mathrm{C}$ for 4 hours, followed by heating at $85{ }^{\circ} \mathrm{C}$ for 5 minutes and cDNA were stored at $-20^{\circ} \mathrm{C}$ until needed.

\section{Molecular detection by Classical -PCR and FMDV serotyping by RT-PCR}

The RT-PCR and PCR were performed using (Advantage $®$ cDNA, Novagen kit). Primarily mastermix containing mixture of $5 \mu 110 \mathrm{X}$ PCR buffer, $3 \mu 125 \mathrm{mM} \mathrm{MgCl} 2,1 \mu 12 \mathrm{mM}$ each dNTPs, $0.5 \mu 1$ Taq DNA polymerase $(5 \mathrm{U} / \mu \mathrm{l})$ and $33.5 \mu \mathrm{LEPC}-\mathrm{H}_{2} \mathrm{O}$ was prepared for each reaction. A total of $44 \mu 1$ of the mastermix, $1.5 \mu 1$ of each of the forward and reverse primer (10 pmol) and $3 \mu l$ of the cDNA were added to each tube. Final the reaction was run on a thermcycler PCR program of initial denaturation at $95{ }^{\circ} \mathrm{C}$ for 2 minute and then 30 cycles of $95{ }^{\circ} \mathrm{C}$ for $1 \mathrm{~min}, 58{ }^{\circ} \mathrm{C}$ for 50 seconds, and $70{ }^{\circ} \mathrm{C}$ for 2 minutes, ending with incubation at $72{ }^{\circ} \mathrm{C}$ for 10 minutes. The amplified products were run into agarose gel electrophoresis.

\section{Agarose gel electrophoresis}

The PCR and RT-PCR products were analyzed on a 1\% agarose gel containing ethidium bromide $(0.5 \mu \mathrm{g} / \mathrm{ml})$. Primarily, a $1 \%$ agarose gel was prepared by weighing 0.5 gram agarose in a $250 \mathrm{ml}$ flask and loaded $50 \mathrm{ml}$ of $0.5 \mathrm{X}$ TAE to it. Then $1 \mu \mathrm{l}$ red gels added and pour in to tank and then place comb. In addition, $1 \mu 1$ loading dye (buffer) was mixed with $5 \mu 1$ PCR product and load these samples in to the prepared well in the gel and run at 120 volt for about 25 minutes in 
parallel with DNA molecular weight marker (Promega Biosciences Inc. in San Luis Obispo, CA, USA) in electrophoresis apparatus. Finally, The DNA bands were visualized by UV transilluminator and the expected sizes were identified against DNA molecular weight markers (Promega Biosciences Inc. in San Luis Obispo, CA, USA).

\section{RESULT}

\section{Clinical Examination of FMD Outbreaks}

The outbreak based cross-section study indicated that cattle and pigs were apparently shown clinical signs of FMDV such as salivation, lameness, vesicle formations on oral cavity, and interdigital vesicles. Moreover, some other animals brought with typical FMDV lesions and sores on the upper and lower pad area and tongue and teats. In line with this, interviewed animal attendants, informed that cattle and pigs with the typical FMDV lesions found difficulty for feeding, walking and drinking water.

\section{Virus isolation and Molecular detection by classical PCR}

All collected samples (20) were cultured on BHK-21 and the cytopathic effects on BHK-21 monolayer cell cultures for FMD virus was observed after 24 hours (Figure 1 and 2), which indicates the presence of the FMDV virus in tissue sample. The CPE is characterized by a fast destruction of the BHK-21 cell monolayer cells and infected cells were found singly and the cell became round in shape. Complete destruction of the cell sheet was mostly observed within 48 hours of inoculation. All inoculated samples showed CPE positivity on cell cultures (Figure 1 and 2). In addition, tissue suspension and cell culture samples were examined by classical PCR, the result revealed that all are detected as positive for FMD virus (Figure 3).

\section{FMDV serotyping by RT-PCR}

The condition of RT-PCR for the serotyping was optimized in similar conditions to the above mentioned PCR protocol, using primers specific for $\mathrm{O}$ serotypes based on published oligonucleotides [16]. The tissue samples examined in RT-PCR revealed that the serotype $\mathrm{O}$ was 
predominantly isolated from all (bovine and swine) clinical samples from Addis Ababa and Bishoftu as summarized in Table 2 (Figure 4).

\section{DISCUSSION}

In the current study, we noted that the FMDV in clinical infected swine and bovine species became more prevalent around Bishoftu and Addis Ababa areas than in the past few years. In the year 2014 to 2017, a total of 35 outbreaks were observed in the country, with the highest outbreak number again in the Oromia region [21].

Primarily, virus-suspected samples were propagated in susceptible cell cultures (e.g. BHK-21) and characterization, which is important to establish the geographic relatedness between isolates, the genetic variation and molecular evolution of viruses in carriers. During outbreaks, it is also important to identify the origin of infection and its relationship to vaccines available for protection, which assist in planning a control and prevention program in the country.

Furthermore, a prompt detection and identification of FMDV and its serotypes is very important for every FMD endemic country to tackle their animal health problems and to implement proper vaccination programs. FMDV is a highly contagious animal disease and can infect all clovenhoofed animals such as cattle, pig, and sheep [5]. The disease is endemic to most countries in sub-Saharan Africa where six of seven serotypes occur, and virus circulates between wild hosts and domestic animals [16]. Ethiopia has large livestock population including both domestic and wild animals. In Ethiopia, FMD is one of the major livestock diseases of socio-economic importance. FMD remains largely uncontrolled in the country, as vaccination for prophylactic purpose is not being practiced save for only a few dairy herds containing exotic animals.

Complementary to the current study, the previous studies (2008-2018) indicated that serotype O was highly prevalent and dominant serotype causing most of the outbreaks in Ethiopia [16]. FMD was first recorded in Ethiopia in 1957 when serotypes $\mathrm{O}$ and $\mathrm{C}$ were detected [22, 23]. Serotypes A and SAT 2 were not identified until 1969 and 1989, respectively [23, 24]. During 1988-1991, Serotypes O and SAT 2 FMDV were identified in Ethiopia as causative agent [24]. Cattle were found to be infected with all circulating types of serotypes, whereas swine had only serotype O. SAT 2 was recorded in 2007 from a bovine sample collected from Bambas, Beneshangul-Gumz, and western Ethiopia bordering Sudan. The first recorded occurrence of 
FMDV SAT 1 in Ethiopia was identified from a bovine sample collected in November 2007 from the MizanTeferi area, which is bordering Kenya. The variations in FMD outbreak results in different places and study period can be related to the coverage of the study area, amount of analyzed samples, lack of consistent disease reports, and priorities of investigators [25].

In the current study, FMDV was isolated from the tissue samples collected from bovine and swine species around Addis Ababa and Bishoftu, Ethiopia. Tissue cultures were used to isolate FMDV from collected samples; each treated samples was passed two successive passages for propagation of FMDV, which appeared as rounding in cells. All (20) samples gave positive

rounding in cell culture. Serotyping of the virus revealed only serotype $O$ was isolated from both species. Virus isolation and typing FMD virus as serotype $\mathrm{O}$ from either tongue epithelium or foot epithelium of clinically infected cattle and swine located in dairy farm, swine farm and in fields showed that serotype $\mathrm{O}$ was prevailed throughout the central Ethiopia. The rapid spread of serotype $\mathrm{O}$ demonstrates the need to have regular surveillance and monitoring systems to determine and respond effectively to FMDV in endemic areas.

\section{CONCLUSION}

FMD is endemic and the major obstacle to the development of livestock due to their adverse effects on livestock production and agricultural export. The epidemiology of FMD in Ethiopia is complex due to the involvement of different domestic and wild host species as well as rooming free cross borders between the neighboring countries and lack of control of animal movements. In addition, lack of prophylactic vaccination and veterinary infrastructure to handle the outbreak on a large scale greatly contributes to the frequent occurrence of the disease and also makes the FMD control extremely challenging. During the study period, only serotype O was recorded throughout the study area. Based on our findings, we advised that sufficient amount of good quality FMD vaccines matching to the endemic serotypes need to be made available. Trivalent FMD vaccines against FMD strain O, A, and SAT2 are mostly produce in the country. Finally, we believed that building capacity in diagnostics, epidemiology and economics to maintain information on the nature of FMDV circulation, regular surveillance and monitoring, and characterization of sub-serotypes/strains for selection of appropriate vaccines strains, domestic livestock movement control during an outbreak from infected area to free areas, and restriction 
of cross border animal movement and establishment of quarantine stations are very critical for applicable control measures for FMD.

$\begin{array}{ll}\text { Abbreviations } & \\ \text { FMDV } & \text { Foot and Mouth Disease Virus } \\ \text { PCR } & \text { Polymerase Chain Reaction } \\ \text { RT-PCR } & \text { Reverse- Transcription- Polymerase Chain Reaction } \\ \text { SAT2 } & \text { South African territory serotypes 2 } \\ \text { BHK-21 } & \text { Baby hamster Kidney-21 } \\ \text { PBS } & \text { Phosphate-buffered saline } \\ \text { CPE } & \text { Cythopathic effect } \\ \text { OIE } & \text { Office International des Epizooties }\end{array}$

\section{Acknowledgements}

We are very grateful for the researcher who is not mentioned as authors and NVI for laboratory for cooperation in the analysis. Moreover, for people who made the information and valuable comments for this research article.

Copyright statement and Consent for publication

All authors confirmed that this manuscript is free from any one's data. All co-authors have affirmed the contents of the manuscript and its publication.

\section{Author's contributions}

Conceptualization; Bisratgebriel Tesfaye Muchie Ashenafi, K.W, and Aklilu Feleke ; investigation and methodology; Bisratgebriel Tesfaye Muchie and Ashenafi, K.W WritingReview and Editing, Ashenafi, K.W , Aklilu Feleke, Zhang,J. Hayelom, Micheal; Final editing, material support; Zhang,J , Ashenafi, K.W, financial support and resource; Zhang, J.

\section{Funding}

This scientific article was supported by the National Key R\&D Program of China (2017YFD0501800, 2016YFD0501500).

\section{Availability of data and materials}

We have no anymore shared raw data and we provided all the details in figures and in tables of this article.

\section{Ethics approval and consent to participate}

We haven't used any animals experiment. The use of any animal data or tissue is not applicable.

\section{Consent for publication}

This manuscript did not contain any person's data.

\section{Competing interests}

The authors declare that they have no competing interests. 


\section{REFERENCE}

1. Knight-Jones TJD, Rushton J. The economic impacts of foot and mouth disease -what are they, how big are they and where do they occur? Prev. Vet. Med. 2013; 112: 3-4.

2. Perry BD, Rich KM. Poverty impacts of foot-and-mouth disease and the poverty reduction implications of its control. Vet. Rec. 2007; 160: 238-241.

3. Vosloo W, Thomson G. Natural habitats in which foot and mouth disease viruses are maintained. In Domingo E and Sobrino F. Foot-and Mouth Disease: Current Perspectives. HorizonScientificPress. 2004; 383-410.

4. Simon M, Firestone YH, Richard B, Takehisa Y, Toshiyuki T, Mark AS. Reconstructing foot-and-mouth disease outbreaks: A methods comparison of transmission network models.Sci. Rep. Nat. 2019; 9: 4809.

5. Donaldson A, Alexandersen S, Sorensen J, Mikkelsen T. Relative risk of the uncontrollable (airborne) spread of FMD by deferent species. Veterinary Record. 2001; 148: 602-604.

6. Anna RS, James AR. NAHEMS Guidelines: Vaccination for Contagious Diseases, Appendix A. Foot and Mouth Disease. Veterinary Microbiology and Preventive Medicine Reports. 2015. Available online: http://www.cfsph.iastate.edu/DiseaseInfo (accessed on 3 October 2019).

7. Pattnaik B, Subramanian S, Sanyal A. Foot- and-Mouth disease: Global Status and Future Road Map for Control and Prevention in India.Agric. Res. 2012; 1: 32-147.

8. Ma J, Xiao J, Gao X, Liu B, Chen H, and Wang H. Spatial pattern of footand-mouth disease in animals in China, 2010-2016.PeerJ. 2017; 5: e4193.

9. Cottam EM, Wadsworth J, Shaw AE, Rowlands RJ, Goatley L, Maan S. Transmission pathways of foot-and-mouth disease virus in the United Kingdom in 2007 PLoS Pathog. 2008; 4: e1000050. 
10. Stevenson M, Sanson RL, Stern MW, O’Leary BD, Moles BN, Morris RS. Interpread Plus:A spatial and stochastic simulation model of disease in animal population. Prev. Vet. Med. 2013; 109: 10-24.

11. Gloster J, Champion H, Rensen S, Mikkelsen J, Ryall T, Astrup D, Alexandersen P, Donaldson SA. Airborne transmission of foot-and-mouth disease virus from Burnside Farm, Heddon-on-the-Wall, Northumberland, during the 2001 epidemic in the United Kingdom. Veterinary Record. 2003; 152: 525-533.

12. FAO. Improved animal health for poverty reduction and sustainable livelihoods. FAO Animal Production and Health. FAO, Rome. 2002; 153.

13. FAO. Foot-and-Mouth Disease situation world and major epidemiological events in 2005-2006. Intelligence information intervention 1.FAO, Rome. 2007.

14. OIE. Quality standard for international guide lines for veterinary laboratories, Infectious Disease des Epizooties (PIE). Paris, France. 2002, 127.

15. Bastos ADS, Boshof CI, Keet DF, Bengis RG, Thomson GR. Natural transmission of foot-and-mouth disease virus between African buffalo (Synceruscaffer) and impala (Aepycerosmelampus) in the Kruger National Park, South Africa. EpidemiologyInfection. 2001; 124: 591-598.

16. Ayelet G, Mahapatra M, Gelaye E, Berhe GE, Rufeal T, Sahle M, Ferris NP. Wadsworth, J.; Hutchings, G.H.; Knowles, N.J. Genetic characterization of foot-and-mouth disease viruses, Ethiopia, 1981-2007. Emerging Infectious Diseases. 2009; 15: 1409-1417.

17. Rufael T, Catley A, Bogale A, Sahle M, Shiferaw Y. Foot and mouth disease in the Borana pastoral system, Southern Ethiopia and implications for livelihoods and international trade. TropAnim. Hlth. Prod. 2008; 40: 29-38

18. Negussie H, Kyule MN, Yami M, Ayelet G, Jenberie ST. Outbreak investigations and genetic characterization of foot and mouth disease virus in Ethiopia in 2008/2009.Trop. Anim. Hlth. Prod. 2010; 43: 235-243.

19. Bayissa B, Bereda A. Assesment of Veterinary Service Delivery, Livestock Disease Reporting, Surveillance Systems and Prevention and Control 
Measures Across Ethiopia/Kenya Border. Enhanced Livelihoods in Southern and Ethiopia (Else Project). CIFA Ethiopia/CARE Ethiopia. 2009.

20. Perrière G, Thioulouse J. Use and misuse of correspondence analysis in codon usage studies. Nucleic Acids Res. 2002; 30: 4548-4555.

21. Ministry of Livestock and Fishery Ethiopia (MoLF).Foot and Mouth Disease Outbreaks Annual Report Recording Data Summary from the Years 20092017; Epidemiology Directorate: Addis Ababa, Ethiopia, 2018.

22. Martel JL. Foot-and-mouth disease in Ethiopia. Distribution of serotypes of foot-and-mouth disease virus. RevElevMedVetPaysTrop. 1974; 27:169-175.

23. Martel JL.Comparative serological study of the principal strains of the foot and mouth disease virus isolated in Ethiopia 19691974.RevElevMedVetPaysTrop. 1975; 28: 287-295.

24. Roeder PL, Abraham G, Mebratu GY, Kitching RP. Foot-and-mouth disease in Ethiopia from 1988 to 1991.TropAnimHealthProd. 1994; 26:163-167.

25. Ashenafi KW, Junfei D, Qian L, Jie Z. Review on Outbreak Dynamics, the Endemic Serotypes, and Diversified Topotypic Profiles of Foot and Mouth Disease Virus Isolates in Ethiopia from 2008 to 2018. Viruses, 2019; 11 


\section{Figures}

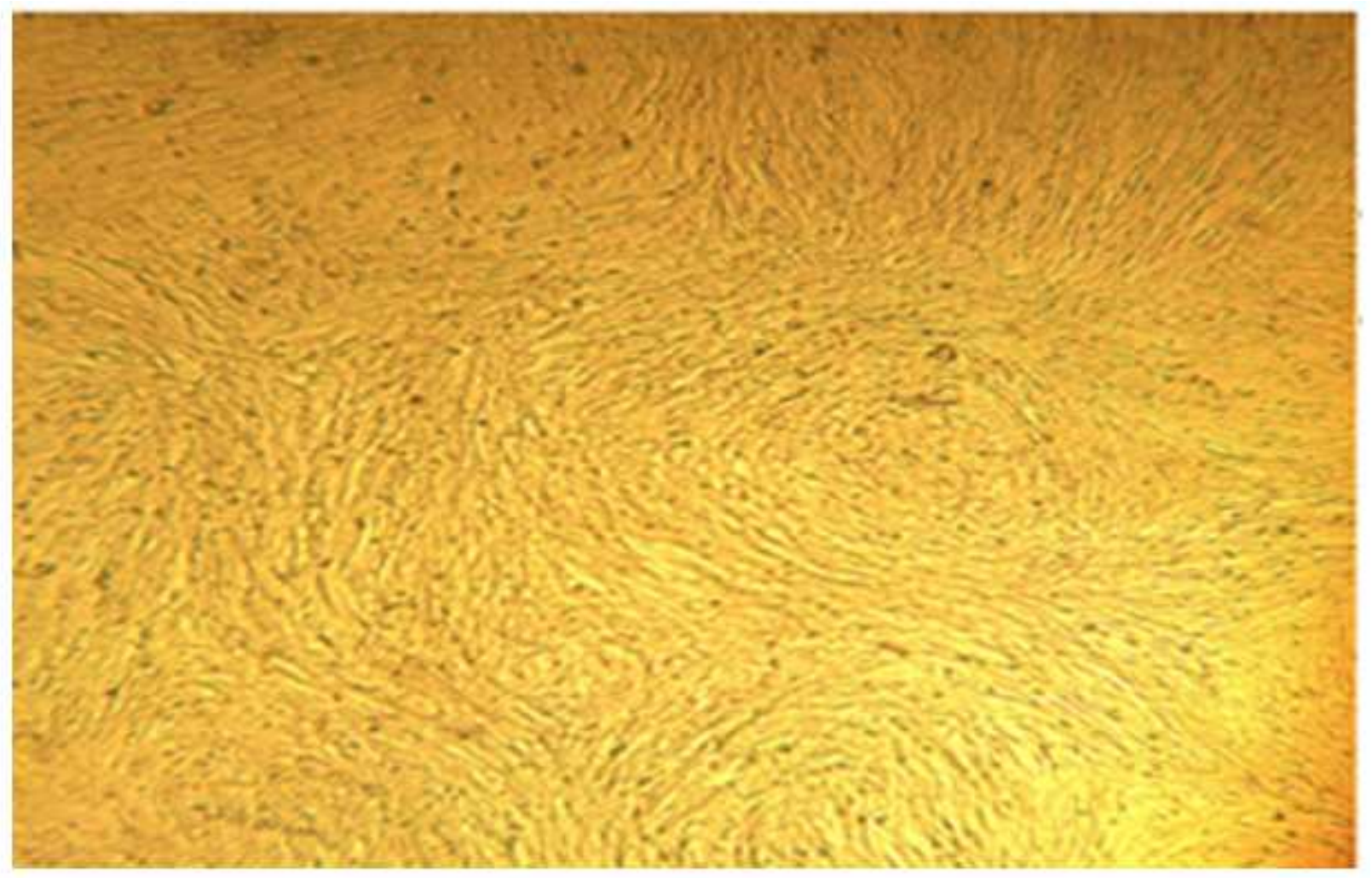

\section{Figure 1}

Indicates the presence of FMDV infected BHK-21 monolayer cells 48 hrs after virus inoculation which characterized by complete destruction and fusion of the infected cells (forming giant cells) and plaque formation 


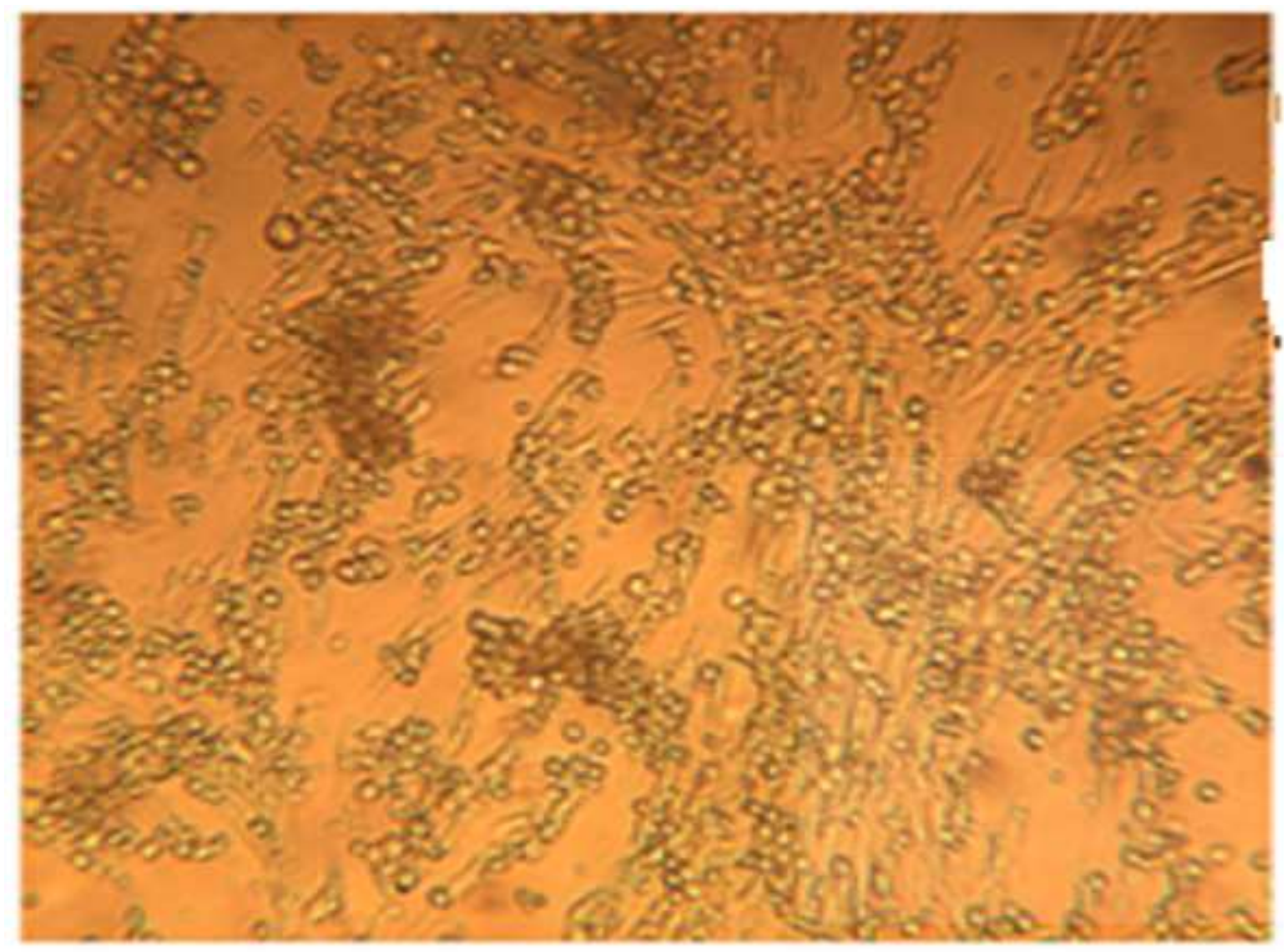

Figure 2

shows high density of healthy BHK-21 monolayer and intact cells. 


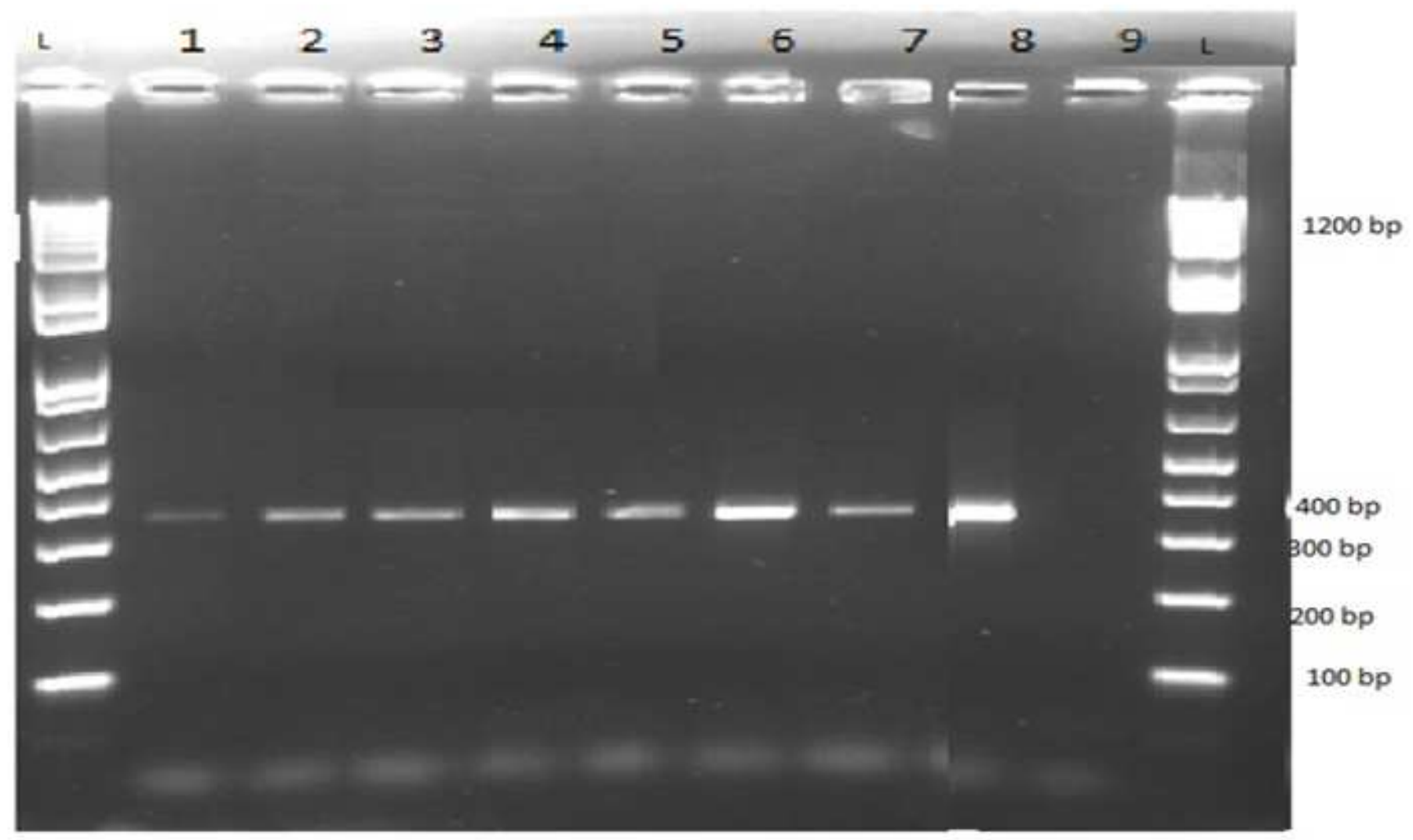

Figure 3

Agarose gel electrophoresis of RT-PCR products for detection of FMD virus by using universal primer. L: DNA Ladder (100bp-0 k bp), Lanes 1-7 are positive FMDV around 328bp. Lane 8 and 9 are positive and negative control respectively. 


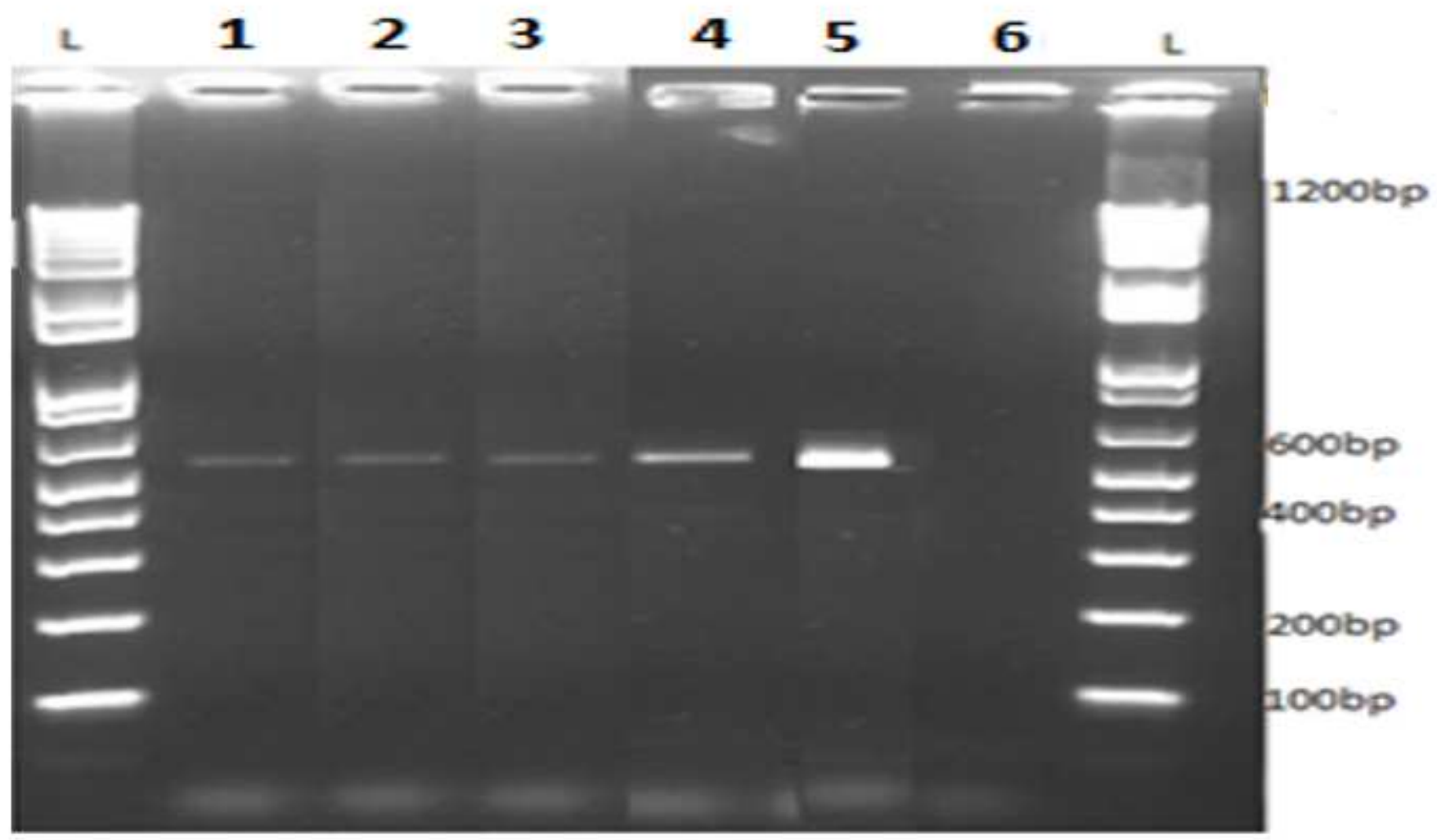

Figure 4

Agarose gel electrophoresis of RT-PCR products for detection of FMD virus serotype "O" by using FMDV “O” primer. L: DNA Ladder (100bp-10 k bp), Lanes 1-4 are positive for FMDV “O” around 591bp. Lane 5 and 6 are positive and negative control respectively. 